
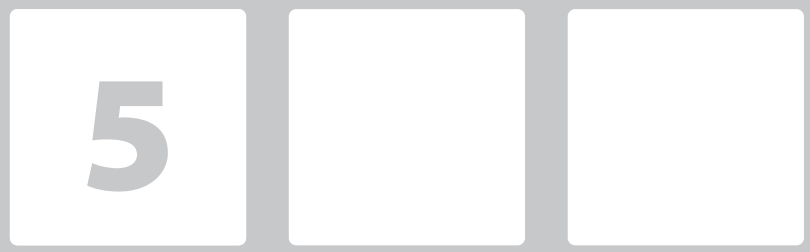

\title{
ANÁLISE DE MATURIDADE DA GESTÃO DO CONHECIMENTO EM UMATUTORIA DE CURSOS DE GRADUAÇÃO A DISTÂNCIA
}

\section{Knowledge Management Maturity Analysis in a Distance Graduation Course Tutorial}

\author{
Mileide Marlete Ferreira Leal Sabino \\ Universidade do Vale do Itajaí - UNIVALI. \\ email:mileide.sabino@gmail.com
}

\section{Marilda Todescat}

Universidade Federal de Santa Catarina - UFSC.

email:marildat@gmail.com

\author{
Neri dos Santos \\ Universidade Federal de Santa Catarina - UFSC. \\ email:nerisantos@gmail.com
}

\section{Alexandre Marino Costa}

Universidade Federal de Santa Catarina - UFSC.

email:marino@cse.ufsc.br

\section{RESUMO}

O objetivo geral deste artigo foi de realizar um diagnóstico do grau de maturidade em Gestão do Conhecimento - GC na Tutoria dos Cursos de Graduação a distância do Departamento de Ciências da Administração da UFSC. Este trabalho é decorrente de um estudo de caso com abordagem quantitativa, caracterizando-se como uma pesquisa descritiva, documental e aplicada, baseada em uma estrutura teórica e conceitual pertinente ao tema. Para a identificação da maturidade em GC, adotaram-se sete critérios baseados no modelo de Batista (2012). A análise das respostas demonstrou que a maioria dos critérios está com o nível baixo de maturidade em GC, com exceção do critério da tecnologia. Os resultados da pesquisa quantitativa mostram um diagnóstico sobre a maturidade em Gestão do Conhecimento, apontando os pontos fortes e oportunidades de melhorias, proporcionado uma orientação quanto às ações e iniciativas para o desenvolvimento de um futuro Modelo de GC para a Tutoria.

Palavras-Chave: Gestão Universitária; Educação a Distância; Tutoria; Gestão do Conhecimento

\section{ABSTRACT}

The general objective of this article was to make a diagnosis of the degree of maturity in Knowledge Management - (GC) in the tutoring of distance courses of graduation at the Department of Administration Sciences at UFSC. This work is the result of a case study with a quantitative approach, characterized as a descriptive, documentary and applied research, based on a theoretical and conceptual structure relevant to the theme. To identify maturity in CG, seven criteria were adopted based on Batista's model (2012). The analysis of the answers showed that most of the criteria have a low level of maturity in GC, with the exception of the technology criterion. The results of the quantitative research show a diagnosis on the maturity in Knowledge Management, pointing out the strengths and opportunities for improvement, providing guidance on the actions and initiatives for the development of a future KM Model for Mentoring.

Key-words: University Management; Distance Education; Mentoring; Knowledge management 


\section{INTRODUÇÃO}

No mundo contemporâneo, as organizações devem estar preparadas para enfrentar e aprender a lidar com uma turbulência de acontecimentos, e um dos principais desafios é a capacidade de gestão do potencial intelectual, caracterizada pela sua complexidade.

Essas constantes mudanças provocam alterações profundas no modo como elas foram, são e serão administradas. As incertezas provocadas pelo processo da Revolução da Informação, desregulação e os novos modelos gerenciais são os grandes desafios que os indivíduos, as organizações e a sociedade têm que enfrentar no cotidiano (SOARES, 2012).

Assim, as organizações compreendem que, ao longo do tempo, o conhecimento torna-se imprescindível e os estudos sobre criação e a gestão do conhecimento organizacional ganham evidência; uma vez que o conhecimento organizacional pode ser visto como impulsionador de desenvolvimento, este tende a evoluir. Por ser o ativo mais importante da organização, é o principal ingrediente do que se produz, se faz, se compra e se vende (STEWART, 1998).

No atual cenário pelo qual passa o Brasil e por consequência as Instituições Públicas, faz-se mais que necessário, o desenvolvimento de um estudo capaz de alavancar uma eficiente Gestão Pública, calcada nos valores essenciais para uma Administração Pública de qualidade, tendo como vetores principais a melhoria dos serviços prestados à comunidade de maneira geral, a maximização dos recursos públicos aplicados e a plena satisfação do servidor público em oferecer serviços de qualidade à sociedade e seus usuários.

Meyer Junior (2000) contribui para este conceito ao afirmar que os administradores públicos, especificamente os universitários, devem romper barreiras internas, estruturais, burocráticas e, principalmente, comportamentais para que as instituições possam se alinhar dentro de uma nova realidade e cumprir a sua missão, prestando serviços relevantes à sociedade.

Importante lembrar que o Brasil, a exemplo de tantos outros países, que já adotam políticas públicas levando em consideração a visão holística na administração, não pode deixar de aplicar um gerenciamento eficaz do conhecimento, onde tem que haver critérios lógicos de manutenção, disseminação, compartilhamento e perenização dos conhecimentos, pois segundo Meyer Junior (2000, p. 142):

\begin{abstract}
A sociedade atual, baseada em alta tecnologia e denominada "sociedade do conhecimento" destaca-se pelo capital intelectual considerado fator crítico, estratégico e diferenciador entre as organizações, países e regiões. Isto coloca as instituições de ensino superior, por definição "organizações do conhecimento", no centro das mudanças. Contudo, esta posição estratégica não está sendo devidamente entendida pelos administradores universitários, pelo setor produtivo e muito menos pela sociedade.
\end{abstract}

As empresas privadas e públicas necessitam de uma implementação da Gestão do Conhecimento para sobreviver na economia da informação (BATISTA, 2012). A Gestão do Conhecimento é um método integrado de criar, compartilhar e aplicar conhecimento para aumentar a eficiência; melhorar a qualidade e a efetividade social; e contribuir para a legalidade, impessoalidade, moralidade e publicidade na administração pública e para o desenvolvimento brasileiro (BATISTA, 2012).

No tocante, Sveiby (2001) elucida que os trabalhadores do conhecimento são os principais responsáveis pela criação de riqueza organizacional. $\mathrm{O}$ sucesso e a sobrevivência das empresas dependem do desempenho de seus colaboradores. Neste caso, a tutoria pode obter a eficiência e eficácia mediante uma gestão do conhecimento integrada à gestão do mesmo. Pois segundo o autor, as organizações somente podem melhorar seu desempenho obtendo o que as pessoas têm de melhor, ou seja, gerenciado as competências de sua equipe a fim de se conseguir maior produtividade e consequentemente melhores resultados.

Nas universidades, a Gestão do Conhecimento (GC) permite que uma organização esteja ciente do conhecimento individual e coletivo que permeia toda sua estrutura, para que possa fazer uso mais eficaz do conhecimento que possui, afinal, são ativos intelectuais.

Diante deste contexto, a gestão do conhecimento na tutoria de educação a distância pode colaborar para um melhor rendimento dos alunos no que se refere à aprendizagem e para a melhoria do desempenho do curso em termos da gestão (NUNES, 2012).

Assim, sob a luz dos referenciais teóricos utilizados neste estudo é que resultaram na proposta deste 
artigo e seu problema de pesquisa: Qual o grau de maturidade em gestão do conhecimento na Tutoria dos Cursos de Graduação na modalidade a distância do Departamento de Ciências da Administração da UFSC?

Para responder o problema de pesquisa, este artigo teve como objetivo geral de realizar um diagnóstico do grau de maturidade em Gestão do Conhecimento na Tutoria dos Cursos de Graduação na modalidade a distância do Departamento de Ciências da Administração da UFSC. E para o alcance deste objetivo, delineou-se os objetivos específicos: a) Verificar o nível de maturidade em gestão do conhecimento na Tutoria; b) Identificar os pontos fortes e oportunidades de melhoria em GC e; c) Propor ações de Gestão do Conhecimento para a Tutoria.

Com a finalidade de verificar a produção científica e as lacunas existentes na área de Gestão do Conhecimento na Administração Pública, foi realizada uma pesquisa no banco de teses e dissertações da Capes no período de publicações de 1987 a 2011 com a expressão exata.

Observa-se nos resultados da busca que a maior concentração de trabalhos relacionados à Gestão do Conhecimento na Administração Pública é em dissertações, representando 42,8\% dos trabalhos totais. Torna-se necessário destacar também que os trabalhos relacionados a temática "Modelos de Gestão do Conhecimento na Administração Pública” não foram encontrados, ou seja, na pesquisa realizada nenhum trabalho foi encontrado nesta temática. Salienta-se que a pesquisa foi realizada com a expressão exata para não fornecer margens para a busca de trabalhos que não abordam diretamente esta área.

Ao realizar uma pesquisa no banco de dados Scopus percebe-se também um reduzido percentual de trabalhos relacionados a Modelos de Gestão do Conhecimento na Administração Pública. Pesquisando-se em artigos a respeito desta temática na área das Ciências Sociais e Humanas, encontrou-se um único trabalho e este ainda se refere a investigar a relação entre as práticas de Gestão do Conhecimento na Alemanha e no Brasil, ou seja, não está relacionado à criação de um modelo específico para a Administração Pública.

Batista (2012) ressalta em sua revisão sistemática sobre a importância dos estudos futuros acerca do tema de gestão do conhecimento na administração pública, onde define que: a) há poucos estudos na literatura de GC na Administração Pública; b) é comum estudos de casos sobre modelos já existentes, mas estes são voltados à administração privada; c) são limitados os estudos contendo modelos de GC genéricos, holísticos e específicos para a Administração Pública; d) os modelos encontrados pelo autor em sua revisão sistemática não apresentam muitas contribuições para a Administração Pública.

Kidwell et al. (2000) alegam que a Gestão do Conhecimento pode melhorar o desempenho da Educação a Distância, ao salientar que o uso de ferramentas de GC na educação a distância podem resultar em melhorias na capacidade de tomada de decisão, redução de tempo de ciclo de produto de desenvolvimento, na melhoria nos serviços acadêmicos e administrativos e redução de custos. Senge (1990, p. 117), declara que "o fundamental no raciocínio sistêmico é a alavancagem - descobrir onde as ações e mudanças na estrutura podem trazer resultados significativos e duradouros. Na maioria das vezes, [...] os melhores resultados não vêm de medidas em grande escala, mas de pequenas ações bem localizadas".

Um modelo de gestão do conhecimento para a tutoria pode contribuir de maneira decisiva para a aplicação de um processo de GC de forma sustentada, além de oportunizar a organização o processo de aprendizagem organizacional, que auxiliará para a renovação continuada do conhecimento. Mas para isso, a tutoria precisa conhecer sua situação atual, isto é, qual é o seu grau de maturidade em gestão do conhecimento, antes de iniciar a implementação da GC.

\section{FUNDAMENTAÇÃO TEÓRICA}

A educação a distância envolve inúmeros aspectos, não foi possível, nessa pesquisa, abordar todos os temas relacionados à modalidade de ensino a distância tampouco explorar as possibilidades e discussões acerca do que será exposto. Por este motivo, esse capítulo irá focalizar sobre a temática da gestão da educação a distância. 


\subsection{GESTÃO DA EDUCAÇÃO A DISTÂNCIA - EAD}

A Educação a Distância é uma modalidade de ensino que demanda elementos essenciais onde também são encontrados na modalidade presencial, tais como: concepção pedagógica, conteúdo específico, metodologia e avaliação, infraestrutura física, tecnológica e de pessoal. No entanto, diferencia-se do presencial, principalmente, no modo de gestão e docência. (MORAES et al., 2007).

Em um curso a distância deve integrar, além da tecnologia de informação e comunicação, um acompanhamento constante de tutores presenciais e a distância, professores, e demais agentes do curso, como, por exemplo, seus gestores. Deve-se ver o processo de educação a distância de forma sistêmica, onde todas as partes estão integradas (NUNES, 2010).

De acordo com Reis (1996), os gestores do processo são as pessoas que gerenciam o todo (visão sistêmica), analisam, supervisionam, controlam e avaliam. O gestor dos processos de um curso a distância é responsável por toda a administração do sistema desenvolvido para dar suporte ao trabalho da equipe.

Dias (2002) complementa que a gestão é interdisciplinar, ou seja, compreende todas as funções (técnica, contábil, financeira, comercial, segurança e administração) e conhecimentos (psicologia, antropologia, estatística, mercadológica e ambiental) necessários, para através de pessoas atingir os objetivos de uma organização de forma eficiente e eficaz. Ainda de acordo com o autor, a gestão tornou-se um aglutinador de conhecimentos das mais variadas áreas do saber, ou seja, possui um caráter multidisciplinar, uma visão sistêmica.

Algumas práticas devem ser repensadas no que concerne às suas estruturas, à organização, ao funcionamento e às suas formas de gestão.

Rumble (1993) destaca que principalmente na gestão de sistemas educacionais, é necessário enfocar os sistemas de educação a distância baseados nos parâmetros da gestão democrática que favoreçam a construção de redes solidárias, com o objetivo de apoiar a produção do conhecimento e do desenvolvimento humano.

O referencial de qualidade do MEC aborda sobre a Gestão acadêmico-administrativa de projetos de educação a distância, onde aborda que a gestão deve ser integradora, estar de acordo com os demais processos da instituição, ou seja, é de suma importância que o aluno encontre um suporte e apoio igualmente oferecido pelo ensino presencial, e o sistema acadêmico deve priorizar isso, no sentido de oferecer ao aluno, geograficamente distante, $\mathrm{o}$ acesso aos mesmos serviços disponíveis para ao do ensino tradicional, tais como: matrícula, inscrições, requisições, acesso às informações institucionais, etc.

Por envolver um conjunto de processos integrados, a gestão de um sistema de educação a distância em nível superior é complexa. É usual no meio de educação a distância a imagem de que o processo de ensino-aprendizagem a distância envolve os vários elos de uma corrente que compõe o "sistema" e de que a robustez do processo, como um todo, está relacionada com o elo mais frágil desta corrente (MEC, 2007).

O MEC (2007) apresenta ainda em seu referencial de qualidade para a educação a distância, os serviços básicos que as Instituições devem apresentar em seu processo de gestão, tais como segue no Quadro 1:

Paulsen (2002) afirma que existem diferentes Sistema de EaD, tais como: Sistemas de Gestão de Conteúdos da Aprendizagem; Sistema de Gestão da Aprendizagem; Sistema de Gestão de Estudantes e Sistema de Gestão Financeira.

Entretanto, Almeida et al. (2006) possuem uma visão diferenciada de Paulsen, pois enxerga a Gestão em EaD a partir de seis dimensões: Gestão de Mídias de Comunicação; Gestão de Materiais; Gestão de Pessoas; Gestão do Tempo; Gestão de Parcerias; e Gestão Administrativa.

Na visão de Terçariol et al. (2008), a Gestão em $\mathrm{EaD}$ compreende apenas duas dimensões: Gestão da Aprendizagem e Gestão Técnica-Administrativa.

As autoras Sartori e Roesler (2005) abordam a Gestão da Educação a Distância de maneira distinta da forma apresentada por Terçariol et al. (2008) e Almeida et al. (2006), pois elas abordam a Gestão do Conhecimento dentro de uma modelagem de Gestão da Educação a Distância. Para as autoras a gestão de EaD compreende quatro dimensões: Gestão da Aprendizagem, Gestão Financeira, Gestão de Pessoas e Gestão do Conhecimento.

Destaca-se a quarta dimensão citada pelas autoras, no que se refere à gestão do conhecimento, pois 
Quadro 1 Processo de Gestão de EaD exigidos pelo MEC

\begin{tabular}{|c|c|}
\hline \multicolumn{2}{|r|}{ Processo de Gestão de EaD exigidos pelo MEC } \\
\hline Serviços & Atividades \\
\hline Sistema de administração & $\begin{array}{l}\text { Controle do processo de tutoria especificando, quando for o caso, os procedimentos logísticos relacionados } \\
\text { com os momentos presenciais e a distância. }\end{array}$ \\
\hline Sistema (logística) & Controle da produção e distribuição de material didático \\
\hline $\begin{array}{l}\text { Sistema de avaliação } \\
\text { de aprendizagem }\end{array}$ & Especificação da logística adotada para esta atividade. \\
\hline Bancos de dados & Deve conter: cadastro de alunos, professores coordenadores, tutores, etc. \\
\hline $\begin{array}{l}\text { Sistema de gestão } \\
\text { dos atos acadêmicos }\end{array}$ & Inscrição e trancamento de disciplinas e matrícula \\
\hline Registros acadêmicos & $\begin{array}{l}\text { Resultados de todas as avaliações e atividades realizadas pelo aluno, prevendo-se, inclusive recuperação e a } \\
\text { possibilidade de certificações parciais. }\end{array}$ \\
\hline Autonomia do professor & $\begin{array}{l}\text { Permitir ao professor ter autonomia para a elaboração, inserção e gerenciamento de seu conteúdo, e que isso } \\
\text { possa ser feito de maneira amigável e rápida, com liberdade e flexibilidade. }\end{array}$ \\
\hline
\end{tabular}

Fonte: MEC (2007).

segundo as autoras, a gestão do conhecimento é um dos pilares básicos para definição de suas estratégias uma vez que implica na produção, armazenagem e distribuição de informações intrinsecamente ligadas ao projeto, e que, são fontes de diagnóstico e ponto de apoio para tomada de decisões por parte da equipe gestora, bem como para o incremento dos níveis colaborativos entre todos os envolvidos. As ações envolvidas na gestão do conhecimento englobam um campo de ação maior que a gestão das tecnologias ligadas à infraestrutura do projeto e às ações pedagógicas, pois envolvem a produção de conhecimento e sua socialização, tendo reflexos tanto em nível interno ao projeto do curso, como avaliação periódica do currículo, oferta de monitoria e incentivo à pesquisa estudantil, quanto externo, no melhor aproveitamento das competências da equipe, na elevação dos níveis comunicativos e de circulação da informação (SARTORI; ROESLER, 2005).

Além disso, de acordo com as autoras, na gestão do conhecimento devem ser previstas políticas permanentes de formação de toda a equipe envolvida no programa que necessitam ser implementadas para acompanhar os avanços da $\mathrm{EaD}$ e do conhecimento, contribuindo para o bom desempenho dos atores envolvidos e nos indicadores de qualidade do curso. Com o aprofundamento das questões teórico-metodológicas e epistemológicas envolvidas na $\mathrm{EaD}$, a instituição estará capacitando-se cada vez mais para o desenvolvimento de programas comprometidos com a realidade brasileira e suas necessidades, estando de acordo com os avanços do conhecimento oferecendo subsídios para a oferta de programas eficazes, ágeis, flexíveis, atualizados e de qualidade.

Ainda na visão de Sartori e Roesler (2005), cabe aos gestores avaliarem constantemente os processos e serviços que viabilizam o funcionamento do programa, pois a avaliação oportuniza análise, diagnóstico e prognóstico do processo, portanto, esse controle possibilita à equipe gestora melhor posicionar-se com relação às estratégias e recursos envolvidos no projeto de curso desde o seu planejamento até sua execução.

\subsection{GESTÃO DO CONHECIMENTO - GC}

"O conhecimento que pode ser expresso em palavras e números representa apenas a ponto do iceberg do conjunto de conhecimentos como um todo." (NONAKA, 2007, p. 65). A finalidade da gestão do conhecimento é que uma organização esteja ciente do conhecimento individual e coletivo que permeiam toda sua estrutura, para que possa fazer uso mais eficaz do conhecimento que possui, afinal, são ativos intelectuais. $\mathrm{O}$ conhecimento organizacional refere-se tanto à experiência física e à tentativa e erro quanto à 
geração de modelos mentais e ao aprendizado com os outros (NONAKA; TAKEUCHI, 1997). De acordo com a Sociedade Brasileira de Gestão do Conhecimento - SBGC (2014), a gestão do conhecimento é reconhecida como um recurso estratégico inserido nas empresas e no cotidiano das pessoas. Ou seja, "é o processo pelo qual a organização gera riqueza, a partir do seu conhecimento ou capital intelectual." (BUKOWITZ; WILLIAMS, 2002, p. 17). Esta riqueza frisada pelos autores acontece quando uma organização aproveita o conhecimento para criar processos mais eficientes e efetivos e utiliza o conhecimento para criar valor para o cliente. Ainda na visão dos autores, "a gestão do conhecimento representa um esforço para reparar prejuízos anteriores e uma política de segurança contra a perda de memória organizacional no futuro." (BUKOWITZ; WILLIAMS, 2002, p. 23).

Para Quintas, Lefere e Jones (1997 apud BINOTTO 2005), a gestão do conhecimento é um processo de gerenciamento crítico do conhecimento para dar suporte às necessidades, identificar e explorar o conhecimento existente, além de adquirir e desenvolver novas oportunidades; é uma atividade mais envolvida com o gerenciamento estratégico e tático dos fatores humanos. Portanto, envolve tanto teoria como prática.

A diferença básica está pautada na gestão do conhecimento, ou seja, está entre aquelas atividades que envolvem a aplicação do conhecimento existente e aquelas que geram novos conhecimentos para a organização, pois os gestores lidam durante a maior parte do tempo com a organização do conhecimento existente (GRANT, 2000 apud BINOTTO, 2005). Sendo assim, para que a gestão do conhecimento efetivamente ocorra, o conhecimento precisa estar atrelado a alguma necessidade e, em alguns casos, precisa sofrer algum tipo de transformação.

Segundo Teixeira Filho (2000, p. 22), "a gestão do conhecimento pode ser vista como uma coleção de processos que governa a criação, disseminação e utilização do conhecimento para atingir plenamente os objetivos da organização". No mesmo enfoque, Moresi (2001, p. 137) afirma que a "gestão do conhecimento pode ser vista como um conjunto de atividades que busca desenvolver e controlar todo o tipo de conhe- cimento em uma organização, visando à utilização na consecução de seus objetivos".

Diante o exposto, Davenport e Prusak (1998) contemplam que a gestão do conhecimento não é algo integralmente novo e sustentam que a GC se baseia em recursos, com os quais a sua organização pode já estar contando, ou seja, uma eficiente gestão de sistema de informação, uma gestão de mudança organizacional e boas práticas de recursos humanos.

A GC é sustentada por quatro pilares: liderança, organização, tecnologia e aprendizado. É o conjunto equilibrado destas forças que viabiliza e permite uma gestão do conhecimento alinhada com a estratégia e que sustenta uma vantagem competitiva para a organização (STANKOSKY; BALDANZA, 2000).

Santos (2000) afirma que na prática, a gestão do conhecimento engloba as seguintes etapas: a) identificação e mapeamento dos ativos intelectuais ligados à organização; b) geração de novos conhecimentos para oferecer vantagens competitivas no mercado; ec) tornar acessíveis grandes quantidades de informações corporativas, compartilhando as melhoras práticas e a tecnologia que torna possível tudo isso - incluindo groupwares e intranets.

\subsection{MODELOS DE MENSURAÇÃO DE GC}

A mensuração da gestão do conhecimento ganhou destaque nas obras literárias acerca da gestão do conhecimento quanto à definição de níveis de maturidade, que representam o estágio em que a empresa está em relação à gestão de seus ativos intangíveis e, especialmente, em relação à GC. Além do destaques em obras literárias, se tornou uma prática amplamente adotada, mas muitas organizações ainda lutam para mensurar os ganhos que ela promete oferecer.

O Nível de maturidade em GC é uma escala de medida onde se pode avaliar a capacidade e o nível de preparação de uma organização em utilizar de forma adequada seus ativos intelectuais ou capital intelectual. Por capital intelectual entende-se o conjunto de ativos intangíveis representado pelo acervo de conhecimentos e geradores do diferencial competitivo, que agregam valor à organização (BATISTA, 2012).

Neste Subcapítulo, descreve-se os modelos existentes sobre a mensuração/avaliação do grau de maturidade em GC de acordo com o Mapa Rodo- 
viário para a Gestão do Conhecimento (Road Map for Knowledge Management Results) da American Productivity andQuality Center (APQC).

Os objetivos desse método são: a) avaliar se as organizações estão implementando de maneira efetiva a GC; b) descrever os passos fundamentais para a efetiva implementação da GC; c) ajudar a organização a identificar em que estágio ela se encontra no processo de implementação da GC; e d) mostrar como começar e indicar a direção mais adequada (BATISTA, 2012).

Segundo Batista (2012) a APQC utiliza de cinco instrumentos para avaliar o grau de maturidade em GC das organizações, a saber:

a) Organizational Knowledge Management (OKA) do Banco Mundial;

b) Prêmio Empresas mais Admiradas do Mundo - Most Admired Knowledge Enterprise (MAKE) - Prêmio MAKE;

c) Modelo de Avaliação do Fórum Europeu de GC;

d) Instrumento para a avaliação da gestão pública do GesPública: um modelo de GC construído para pequenas e médias empresas pela $\mathrm{APO}$;

e) Questionário de pesquisa utilizado pela Organização para Cooperação e Desenvolvimento Econômico (OCDE).

Neste artigo, a autora escolheu o modelo de Batista (2012) para realizar o diagnóstico da maturidade de GC proposto como objetivo deste estudo.

Para Batista (2012), os objetivos do Instrumento de Avaliação da Gestão do Conhecimento são:

- Determinar o grau de utilização da Gestão do Conhecimento na organização pública;

- Determinar se a organização pública conta com condições adequadas para implementar e manter de forma sistemática os processos de Gestão do Conhecimento;

- Identificar os pontos fortes e oportunidades de melhoria da Gestão do Conhecimento.

Para o autor, antes de iniciar a implementação da GC, a organização pública precisa conhecer sua situação atual, isto é, qual é o seu grau de maturidade em Gestão do Conhecimento.
Batista (2012) então elaborou o instrumento para avaliar o grau de maturidade em GC baseado em seu Modelo de Gestão do Conhecimento para a Administração Pública criada por ele, e que, inclusive, se tornou base para este estudo e é apresentado nos subcapítulos posteriores. $\mathrm{O}$ instrumento avalia os seguintes eixos:

1. Direcionadores estratégicos: visão, missão, objetivos estratégicos, estratégias e metas. Ajudam a identificar a analisar as competências essenciais.

2. Viabilizadores: Liderança, tecnologia, pessoas e processos. Contribuem para entender até que pontos esses fatores estão presentes na organização.

3. Processos de GC: identificar, criar, armazenar, compartilhar e aplicar conhecimento.

4. Ciclo KDCA: auxilia na realização de um mapeamento inicial das práticas de GC existentes na organização que podem ser disseminadas durante a implementação.

5. Resultados Esperados: medem a efetividade do processo de GC apoiado pelos fatores críticos de sucesso ou viabilizadores e fundamentados nos direcionadores estratégicos.

São sete os critérios de avaliação da Gestão do Conhecimento que integram o instrumento de Batista para mensurar o grau de maturidade em GC, a saber: a) Liderança em Gestão do Conhecimento; b) Processo; c) Pessoas; d) Tecnologia; e) Processos de GC; f) Aprendizagem e Inovação e; g) Resultados da GC.

Com base na pontuação obtida na aplicação do instrumento de avaliação, é possível identificar o nível de maturidade em GC que a organização se encontra. A Figura 1 apresenta os cinco níveis de maturidade em GC propostas e no qual Batista adotou para mensurar o nível de maturidade de GC em instituições públicas (BATISTA, 2012).

O Instrumento de Avaliação da Gestão do Conhecimento de Batista adota 42 questões baseada nos sete critérios descritos anteriormente. Os resultados da avaliação mostrarão o grau de maturidade em GC da organização pública. Esse grau pode variar do nível "reação" que se trata do nível mais baixo 
Figura 1 Níveis de Maturidade em GC

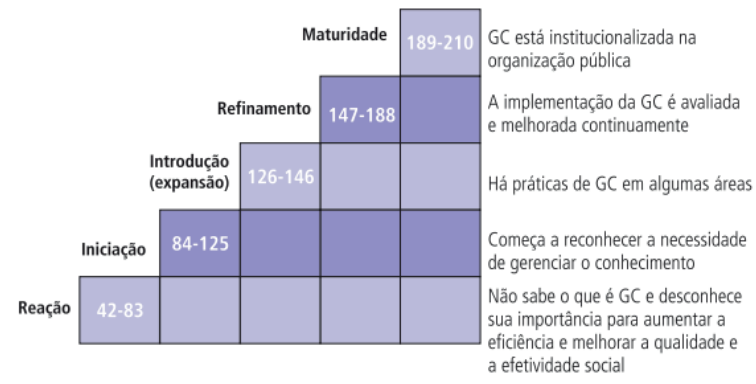

Fonte: APO (2009 apud Batista, 2012).

até o nível "maturidade" se refere ao nível mais alto (BATISTA, 2012).

Batista (2012) argumenta em seu modelo que, após apurado os resultados do instrumento de avaliação de GC aplicado, elabora-se o Business Case da GC para justificar a importância da GC para a organização pública. Com os resultados da avaliação do grau de maturidade em GC e conhecendo onde estão localizados seus pontos fortes e oportunidades de melhoria, a organização pública pode agora justificar a importância da GC.

\section{PROCEDIMENTOS METODOLÓGICOS}

Uma das pesquisadoras trabalhou na Tutoria de Educação a Distância do Curso de Administração, que fez parte do campo da pesquisa; a forma de acesso foi direta, uma vez que, como Supervisora de Tutoria, atuou em todas as etapas do estudo.

Neste estudo, no que se refere ao delineamento da pesquisa, quanto aos fins (objetivos)se classifica como uma pesquisa descritiva e aplicada.

Como se pretendeu, no presente estudo, realizar um diagnóstico do grau de maturidade em Gestão do Conhecimento na Tutoria de Educação a Distância, a pesquisa descritiva se tornou necessária a este objetivo, pois se observou, analisou e pesquisou, ou seja, a descrição dos dados analisados e a construção do referencial teórico. De acordo com Köche (2001, p.124), a pesquisa descritiva "estuda as relações entre duas ou mais variáveis de um dado fenômeno sem manipulá-las".
Este estudo é caracterizado quanto à sua natureza como uma pesquisa aplicada, que para Vergara (2007) é motivada pela necessidade de resolver problemas reais. Dessa forma, buscou-se responder a questões de ordem prática, visando fornecer subsídios para uma futura implementação de um plano de GC para a Tutoria.

Quanto aos meios (procedimentos técnicos), se caracterizam como pesquisa bibliográfica, pesquisa documental e estudo de caso.

A pesquisa bibliográfica, como afirma Köche (2001, p.122), é aquela que explica um problema "utilizando o conhecimento disponível a partir das teorias publicadas em livros ou obras congêneres". Este tipo de pesquisa tornou possível fazer-se a fundamentação teórica, por meio de material publicado em livros, revistas, artigos científicos, isto é, material disponível aos pesquisadores de uma forma geral como fontes secundárias.

Em relação à pesquisa documental, esta se fez a partir de materiais que não receberam tratamento analítico, ou seja, a fonte dos dados foram documentos da tutoria (arquivos públicos), incluindo os ofícios, portarias, resoluções, memorandos e relatório de atividades da tutoria.

Quanto ao caráter desta pesquisa como estudo de caso, Triviños (1987) relata que os mesmos têm como finalidade aprofundar a descrição de determinada realidade e que os resultados do estudo de caso são válidos para o caso que se estuda, não podendo ser generalizado. Utiliza-se o estudo de caso em algumas situações, para contribuir com conhecimento que se tem dos fenômenos individuais, organizacionais, sociais, políticos e de grupo, além de outros fenômenos relacionados. Este estudo aprofundou-se na realidade da Tutoria dos Cursos de Graduação na modalidade a distância do Departamento de Ciências da Administração da UFSC, no que diz respeito aos aspectos relacionados ao grau de maturidade em GC nos seis projetos existentes dentro da Tutoria.

A pesquisadora optou por realizar apenas a etapa 01 (diagnóstico da organização) do modelo de Batista (2012) citado no referencial teórico, pois o foco foi a elaboração de um diagnóstico acerca do nível de maturidade em Gestão do Conhecimento na Tutoria dos Cursos de Graduação na modalidade a distância do Departamento de Ciências da Administração da 
UFSC.A delimitação do estudo, deveu-se aos limites de tempo para o desenvolvimento da pesquisa e, também, por considerar que cada departamento possui suas particularidades no que se refere à gestão, ao compartilhamento do conhecimento e a outros aspectos, o que poderia dificultar as análises das situações diferenciadas no estudo. Assim, optou-se por dar ênfase restrita a Tutoria do Departamento de Ciências da Administração - CAD. Com esta finalidade, a pesquisa tem como objeto de análise uma unidade que pertence a uma organização pública, a tutoria, no período de 2011 a 2014, desenvolvendo temas relacionados à Gestão Universitária, Educação a Distância, Conhecimento, Gestão do Conhecimento, Modelos em Gestão do Conhecimento e Maturidade em Gestão do Conhecimento.

Se utilizou do Censo para a aplicação do Instrumento de Avaliação da GC (Grau de Maturidade) na Tutoria, pois foi aplicado à todos os integrantes da equipe da Tutoria, um total de 53 participantes (excluindo a pesquisadora).A População alvo foi a Tutoria dos Cursos de Graduação na modalidade a distância do Departamento de Ciências da Administração da UFSC e os sujeitos da pesquisa foram: o Chefe de Departamento, a Subchefe de Departamento, os Coordenadores de Curso, os Coordenadores de Tutoria, o Coordenador de TI, os Supervisores de Tutoria, os Tutores a distância, os Técnicos de Informática e a Bibliotecária.

Para efetuar a coleta dos dados a serem analisados, utilizou-se de dois tipos: a observação participante e o questionário como forma de obtenção de dados para a pesquisa e a elaboração do diagnóstico proposto.No que se refere à aplicação do questionário, este foi utilizado para a mensuração do grau de maturidade da GC na tutoria. Como a Tutoria possui muitos tutores e estes trabalham boa parte das horas à distância, selecionou-se o questionário como a forma apropriada para a coleta de dados. Quanto ao método de aplicação do questionário, este foi aplicado na Tutoria dos Cursos de Graduação na modalidade a distância do Departamento de Administração da UFSC, onde foram distribuídos 53 questionários por e-mail, aos integrantes da tutoria, disponibilizando o questionário por meio de um link de acesso ao Google Docs. O questionário foi realizado sem a identificação do respondente, sendo assim, tinha-se a expectativa de se obter "respostas mais confiáveis e seguras para análise dos dados" (LAKATOS; MARCONI, 1996, p. 75). Foram seguidos os seguintes procedimentos:

1. Cada integrante da equipe respondeu individualmente o questionário de pesquisa;

2. Foi fornecido um prazo de dez dias (26/05/14 a $03 / 06 / 14)$ para o preenchimento dos questionários;

3. Dividiu-se toda a equipe em quatro grupos: a) grupo da Alta Administração que corresponde ao Chefe de Departamento, a Subchefe de Departamento, aos Coordenadores de Curso e aos Coordenadores de Tutoria; b) grupo da Supervisão que integra os supervisores de tutoria de todos os projetos existentes na tutoria; c) grupo da TI que corresponde ao Coordenador de TI e os Técnicos de Informática e; d) grupo dos Tutores que conta com todos os Tutores a distância que trabalham na Tutoria.

$\mathrm{Na}$ devolutiva dos questionários aplicados, notou-se que houve 49 respostas das 53 enviadas, representando assim 92\% dos questionários respondidos.Nesta etapa de coleta de dados, realizou-se uma autoavaliação na tutoria para mensurar o grau de maturidade em GC utilizando uma adaptação do Instrumento para Avaliação da GC na Administração Públicade Batista (2012), conforme foi apresentado na fundamentação teórica deste estudo. Com base na pontuação obtida na aplicação do instrumento de avaliação, foi possível identificar o nível de maturidade em GC que a tutoria se encontrava. A Figura 1 apresenta os cinco níveis de maturidade em GC propostas e no qual Batista (2012) adotou pra mensurar o nível de maturidade de GC em instituições públicas.

Os objetivos dessa autoavaliação são de: determinar o grau de utilização da GC na tutoria; determinar se a tutoria conta com condições adequadas para implementar e manter de forma sistemática os processos de GC; e identificar os pontos fortes e as oportunidades de melhoria da GC.

O outro método de coleta de dados foi o da observação. A coleta de dados teve a autora como observadora participante de todo o processo. Para Marion (2006, p. 90), a observação "é uma técnica de coleta de dados para conseguir informações e utiliza 
os sentidos na obtenção de determinados aspectos da realidade". Durante o estudo, foi realizado a observação da tutoria, ou seja, foi observado todos os procedimentos que são estabelecidos nos processos de trabalho, as demandas de serviços, a forma de atuação dos tutores, a forma de atuação dos supervisores, a forma de atuação da técnica, a forma de atuação das coordenações e também o processo de construção do conhecimento na tutoria, a fim de estabelecer parâmetros para o tratamento dos dados qualitativos. A observação, que é um requisito do método indutivo previamente adotado, desempenhou um papel importante no estudo, pois, segundo Barros e Lehfeld (1986, p.61), "observar é aplicar atentamente os sentidos a um objeto para de ele adquirir um conhecimento claro e preciso. É um procedimento investigativo de suma importância na ciência, pois é através dele que se inicia todo o estudo de problemas".

O presente trabalho de pesquisa, dada à natureza de seu objeto, teve como abordagem quantitativa. Os dados foram coletados a partir de um questionário, aplicou-se a adaptação do Modelo de Instrumento de Avaliação da GC apresentado por Batista (2012) e com base no "Manual de Implementação da Gestão do conhecimento (GC) na Administração Pública” de Batista (2012). Com as 43 perguntas do questionário aplicado, pode-se chegar ao resultado do grau de maturidade em Gestão do Conhecimento da tutoria e estes foram tratados a partir de sete critérios de análise, a saber: Liderança em Gestão do Conhecimento(Perguntas de 01 a 06), Processo(Perguntas de 07 a 12), Pessoas(Perguntas de 13 a 18), Tecnologia (Perguntas de 19 a 24), Processos de GC (Perguntas de 25 a 30), Aprendizagem e inovação(Perguntas de 31 a 36) e Resultados de Gestão do Conhecimento(Perguntas de 37 a 42).

\section{APRESENTAÇÃO E ANÁLISE DOS RESULTADOS}

Durante a realização do estudo, a tutoria contava com aproximadamente 54 colaboradores para o desenvolvimento das atividades de aprendizagem dentro da tutoria, distribuídos em: 2 Coordenadores de Curso, 2 Coordenadores de Tutoria, 1 Coordenador de TI, 5 Supervisores de Tutoria, sendo uma desta a Supervisora dos Tutores Presenciais que ficam alocados nos Polos de Apoio Presencial, 4 Técnicos de Informática, 1 Bibliotecária Documentalista, 3 estagiários para a recepção e 36 Tutores a distância que realizam plantões de 4 horas semanais e 16 horas virtualmente.

O regime de trabalho na tutoria é de 20 horas semanais para os tutores, sendo que dessas, 4 são presenciais, ou seja, devem ser cumpridas no ambiente da tutoria em um horário previamente estipulado e seguindo uma escala de trabalho, já as 16 horas restantes devem ser cumpridas virtualmente. Além disso, o tutor a distância deve comparecer a tutoria em momentos de capacitações e reuniões. E ainda, devem participar de determinados momentos presenciais que acontecem nos Polos de ensino.

Para os técnicos de informática que fazem parte da equipe de TI da tutoria, estes também cumprem 20 horas semanais, porém, presencialmente e seguindo uma escala de trabalho.

Já os supervisores de tutoria, cumprem 30 horas semanais, sendo que dessas, 20 são presenciais, ou seja, devem ser cumpridas no ambiente da tutoria em um horário previamente estipulado e seguindo uma escala de trabalho, já o restante deve ser cumprido virtualmente.

O chefe de departamento, o subchefe de departamento, os coordenadores de curso, os coordenadores de tutoria e o Coordenador de TI, estes cumprem o horário determinado pelo Departamento, sendo compartilhado entre suas funções de professores, na grande maioria no período integral.

Os agentes elencados que fazem parte da estrutura da tutoria constituem um papel importante para o funcionamento da Tutoria e do Curso. Cada qual tem determinadas funções e atividades que contribuem para o andamento do processo tanto administrativo quanto pedagógico.

\subsection{PERFIL DOS SUJEITOS DA PESQUISA}

No total, atuam 36 tutores a distância na Tutoria do CAD, 5 Supervisores de Tutoria, 4 integrantes da TI, 3 Coordenadores de Curso, 2 Coordenadores de Tutoria, um Coordenador de TI, uma Bibliotecária, um Chefe de Departamento e um Subchefe de Departamento. Optou-se pela realização da pesquisa 
com os tutores dos projetos PP1, PP2, UAB1, UAB2, PNAP1 e PNAP2.Responderam ao questionário on-line 33 tutores a distância, representando 67\% dos respondentes, 4 Supervisores, totalizando $8 \%$ dos respondentes, 4 integrantes da TI também reproduzindo $8 \%$, 3 Coordenadores de Curso com a representação de 6\%, 2 Coordenadores de Tutoria com $4 \%$, um Coordenador de TI com $2 \%$, um Chefe de Departamento totalizando 2\% e um Subchefe de Departamento representando também $2 \%$ no total dos respondentes. A Tabela 2 destaca o perfil dos pesquisados e que fazem parte da equipe da tutoria.

Pode-se observar durante a coleta de dados que a maior representatividade dos pesquisados encontram-se na faixa etária entre 26 e 32 anos, representando um total de $59 \%$ dos pesquisados. Na equipe predomina o sexo feminino (67\% dos indagados) e a há uma homogeneidade entre o estado civil, pois fica evidenciado pelas porcentagens de $49 \%$ terem declarado ser solteiros e $47 \%$ casados.

Destaca-se nos resultados da pesquisa que a tutoria conta com uma equipe com alto índice de conhecimento, pois boa parte dos questionados possui como nível de escolaridade a especialização completa, representando $37 \%$ do total da população estudada. Conforme pode ser visualizado no Gráfico 1, há uma evidência desta afirmação ao constatar que $28 \%$ ou estão cursando ou já concluíram o mestrado, seguido de $17 \%$ com Doutorado concluído e $8 \%$ em andamento. Ou seja, fica demonstrado que a tutoria conta com uma equipe com alto índice de conhecimento, mas de acordo com Probst, Raub e Romhardt (2002), um know-how em si não é suficiente, o que se torna mais imprescindível é saber o que pode ser feito com este conhecimento. "A grande finalidade do conhecimento não é conhecer, mas agir" (DAVENPORT; PRUSAK, 1998).

A equipe também foi questionada a respeito de aspectos relacionados ao tempo de atuação na tutoria, a função exercida e o turno de serviço. Constatou-se que os pesquisados, em parte, atuam de forma sólida na Tutoria dos Cursos de Graduação a Distância do Departamento de Administração da UFSC, de acordo com os resultados nota-se que há pouca rotatividade da equipe, $31 \%$ do total da equipe responderam que estão de 2 a 3 anos na tutoria e $27 \%$ responderam estar de 4 a 5 anos. Apenas 14\% está há menos de um ano atuando na tutoria. Se somadas ambas as categorias com a maior porcentagem, tem-se $58 \%$ da equipe em exercício das atividades na tutoria entre um período de 2 a 5 anos. No que se refere ao período/turno de trabalho na tutoria, observa-se que as respostas se subdividem entre "manhã" e "noite", com 18\% e 17\% das respostas respectivamente. Constatou-se também que a maior parte da equipe da tutoria é composta por tutores a distância, com um total de 33 das respostas (68\% do total) entre os 49 pesquisados.

Observa-se que predominantemente a equipe da tutoria dos cursos de graduação a distância do Departamento de Administração da UFSC são do sexo feminino, com idade de 26 a 32 anos, solteiros e com especialização concluída como nível de escolaridade. Além disso, verifica-se que os mesmos exercem suas funções na tutoria de 2 a 3 anos, a predominância da função é de tutor a distância e praticam suas atividades nos períodos da manhã e noite.

\subsection{GRAU DE MATURIDADE EM GC DA TUTORIA: VISÃO DOS PESQUISADOS}

Com o intuito de atingir os objetivos deste estudo buscou-se diagnosticar se a tutoria está ou não fazendo a gestão do conhecimento, realizando uma autoavaliação do grau de maturidade em GC utilizando o Instrumento adaptado de Batista (2012) para avaliação da GC na Administração Pública. Este diagnóstico possui o objetivo de analisar os quatro viabilizadores de GC proposto no modelo, a saber: liderança, tecnologia, pessoas e processos. Esta análise dos quatro viabilizadores da GC contribuirá para compreender até que ponto esses fatores estão presentes na tutoria.

A finalidade desta avaliação é de conhecer a situação atual, isto é, o seu grau de maturidade em GC para poder ser iniciado futuramente uma jornada de implementação da GC na tutoria.Para a aplicação do questionário, como já mencionado nos procedimentos metodológicos desta pesquisa, dividiu-se a equipe em quatro grupos: 1) ocupantes do cargo da Alta Administração; 2) ocupantes do cargo de Supervisão de Tutoria; 3 ) colaboradores que atuam na TI; e 4) ocupantes do cargo de Tutor (a).

Após a realização da pontuação de cada grupo correspondente à equipe da tutoria, se 
fez necessário pontuar a visão geral dos grupos e obter uma média das pontuações, conseguindo assim, chegar ao nível de maturidade que se encontra a Tutoria. No Gráfico 1 ilustra a posição do nível de maturidade em GC da tutoria.

Gráfico 1 Pontuação por Critério de Avaliação da Gestão do Conhecimento - Média dos grupos
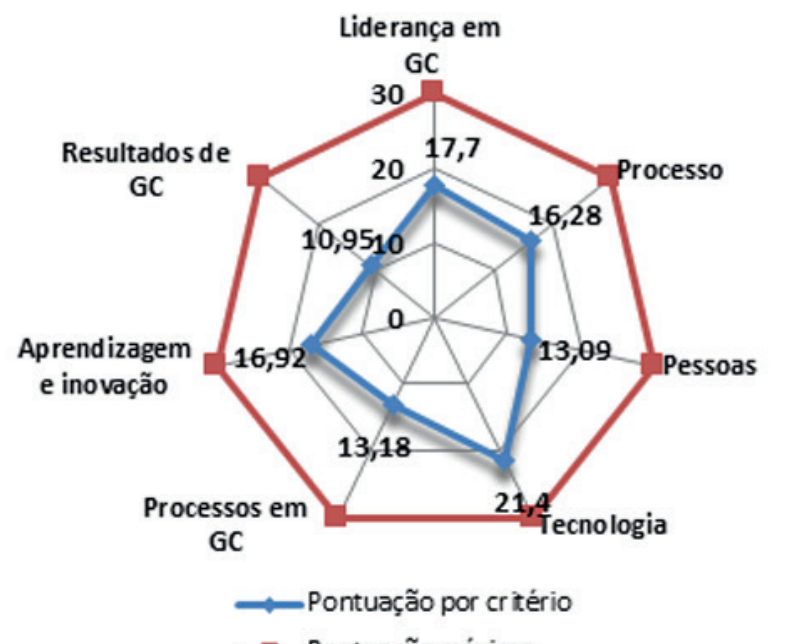

- Pontuação máxima

Fonte: Dados primários (2014).

Observa-se com os registros das pontuações alcançadas nas respostas dos grupos de uma forma geral, que após a realização de uma média (PT/4) onde a Pontuação Total é dividida pelo ${ }^{\circ}$ de grupos, que seriam quatro, chegou-se ao resultado de que em primeiro lugar ficou o critério 4.0, referente à tecnologia, com a média da pontuação total dos grupos de 21,4 em relação à pontuação máxima que seria 30 . Em segundo lugar ficou o critério 1.0, que se refere à liderança em GC, com a média da pontuação de 17,7 em comparação à pontuação máxima. Em terceiro lugar ficou o critério 6.0, que diz respeito à aprendizagem e inovação, com a média da pontuação em 12. Em quarto lugar ficou o critério 2.0, processos, com a pontuação média de 16,28. Em quinta colocação ficou o critério 5.0, que se trata dos processos de GC, com a pontuação média de 13,18 . Em sexto lugar ficou o critério 3.0, que se refere às pessoas, com a pontuação média de 13,9. E em última colocação, ficou o critério 7.0, referente aos Resultados da GC, o critério que apareceu em todos os grupos em último lugar, com a pontuação média de 10,95.
No Gráfico 1 é possível, com base na pontuação média final obtida pelos grupos, identificar o nível de maturidade em GC que a tutoria se encontra em cada critério. A pontuação máxima alcançada com a soma das médias obtidas com os grupos em cada critério totalizou em 109,52, comparado à soma total das pontuações que seria 210 .

Analisando o critério Liderança em GC que se refere às perguntas de $01 \mathrm{a} 06$, pode-se concluir que este critério ficou em segundo lugar com a maior pontuação obtida nas respostas e com a representatividade de 17,7 em relação à pontuação máxima que é 30. Este critério se refere ao alinhamento da GC; a existência de arranjos organizacionais para formalizar as iniciativas de GC; recursos para as iniciativas de GC; política de proteção do conhecimento; e por fim, se a alta administração e chefias intermediárias servem de modelo de compartilhamento do conhecimento e de trabalho colaborativo e se promovem, reconhecem e recompensam a melhoria do desempenho, o aprendizado, o compartilhamento e criação do conhecimento e inovação. Observa-se que neste critério houve uma concordância nas respostas dos grupos, pois três grupos colocaram este critério como em segundo lugar.

Segundo Batista (2012, p. 56 ), “a liderança ou alta administração desempenha um papel fundamental para o sucesso da implementação da GC nas organizações”. Ainda na visão do autor, compete, também, à liderança estabelecer a estrutura de governança e os arranjos organizacionais para formalizar as iniciativas de GC.

Referente ao segundo critério, o Processo que trata das perguntas de 07 a 12 do questionário, constata-se que este teve homogeneidade nas respostas, ficando em terceira colocação na opinião de dois grupos e na quarta colocação na opinião dos dois grupos restantes. Este critério ficou com a representatividade de 16,8 em relação à pontuação máxima. Neste critério é avaliado sobre as competências essenciais da tutoria; modelagem dos sistemas de trabalho; sistema de gerenciamento de crises ou eventos imprevistos; implementação e gerenciamento de processos de apoio para assegurar atendimento; e por fim, se a tutoria avalia e melhora continuamente seus processos para alcançar melhor desempenho. 
No que tange ao terceiro critério, as Pessoas, que corresponde as perguntas 13 a 18 do questionário, três grupos classificaram como quinto colocado e um grupo como sexto colocado, sobressaindo assim a $5^{\text {a }}$ colocação com 13,9 da representatividade em relação à pontuação máxima. Neste critério é avaliado os programas de educação e capacitação da tutoria, se estas ampliam o conhecimento, as habilidades e a capacidade dos que trabalham na tutoria e apoiam o alcance dos objetivos da tutoria; se a organização dissemina informações sobre benefícios, política, estratégia, modelo, plano e ferramentas de GC para novos funcionários; se a tutoria possui processos formais de "mentoring" ou "coaching"; e por fim, se a tutoria conta com um banco de competências; se há reconhecimento e recompensa quando alguém da equipe colabora e compartilha conhecimento; e se a organização do trabalho realizado na tutoria contempla trabalho em equipe.

As pessoas desempenham um papel importante nos processos principais de GC. Pois são elas que identificam, criam, armazenam e aplicam conhecimento. Isso contribuirá para alcançar os objetivos e melhorar o desempenho da organização (BATISTA, 2012).

Ao examinar o quarto critério, a Tecnologia, este referente às perguntas 19 a 24, foi unânime entre os grupos, obteve a colocação de primeiro lugar com uma representatividade de 21,4. Neste critério é verificado se há infraestrutura de tecnologia da informação como apoio à GC; se a infraestrutura de TI está alinhada com a estratégia de GC da Tutoria; se todas as pessoas têm acesso ao computador; se todas as pessoas têm acesso a internet e a um endereço de e-mail; se as informações disponíveis no sitio de Rede Mundial de Computadores são atualizadas regulamente; se a intranet é usada como fonte principal de comunicação e como apoio à transferência de conhecimento e ao compartilhamento da informação.

De acordo com Batista (2012), a tecnologia viabiliza e acelera os processos de GC por meio de práticas efetivas (ferramentas e técnicas) e contribuem para a criação, o armazenamento, o compartilhamento e a aplicação do conhecimento. Além disso, facilita a colaboração presencial e virtual melhorando a comunicação e o compartilhamento tanto no nível formal como no informal.
No que diz respeito ao quinto critério, Processos de GC, que se refere as perguntas 25 a 30 e com 13,18 da representatividade, este se sobressaiu na sexta colocação na opinião de três grupos e na quinta colocação na visão de apenas um grupo. Neste critério examina-se os processos sistemáticos de identificação, criação, armazenamento, compartilhamento e utilização do conhecimento; se a Tutoria conta com um mapa de conhecimento e o utiliza; se o conhecimento adquirido é registrado e compartilhado; se o conhecimento essencial de alguém da equipe que está saindo da Tutoria é retido; se a Tutoria compartilha as melhores práticas e lições aprendidas; e se há benchmarking interno e externo para melhorar o desempenho e inovar. Este critério ficou em penúltimo lugar em uma visão geral e é preocupante, pois seria a essência, não mais importante, porém de grande significância no gerenciamento da GC.

Na visão de Batista (2012, p. 60), os "processos sistemáticos e modelados de maneira efetiva podem contribuir para aumentar a eficiência, melhorar a qualidade e a efetividade social e contribuir para a legalidade, impessoalidade, publicidade e moralidade na administração pública e para o desenvolvimento nacional".

Referente ao sexto critério, a Aprendizagem e Inovação, que é indagado nas perguntas 31 a 36 do questionário, este obteve uma representatividade de 16,92 em relação à pontuação máxima e sobressaiu a terceira colocação na visão de dois grupos, tendo os outros dois grupos optado pela quarta e segunda colocação. Neste critério é avaliado se a Tutoria articula e reforça como valores a aprendizagem e inovação; se a Tutoria aceita o erro como oportunidade de aprendizagem; se há equipes interfuncionais para resolver problemas; se as pessoas recebem autonomia dos seus superiores hierárquicos; se as chefias intermediárias estão dispostas a usar novas ferramentas e métodos; e se as pessoas são incentivadas a trabalhar junto com outros e a compartilhar informação.

Ao analisar o último critério, Resultados de Gestão do Conhecimento, que diz respeito às perguntas 37 a 42 , este demonstrou uma representatividade de 10,95 no total e ficou unanimemente perante os grupos em última colocação. Neste critério é analisado se a Tutoria possui histórico de implementação da GC; se são utilizados indicadores para avaliar o 
impacto das contribuições e das iniciativas de GC nos resultados da tutoria; se a Tutoria melhorou graças às contribuições da GC - os resultados relativos aos indicadores de eficiência; aos indicadores de qualidade; aos indicadores de efetividade social; e referente aos resultados dos indicadores relativos a legalidade, impessoalidade, publicidade, moralidade e desenvolvimento.

Isso demonstra que o resultado obtido na mensuração do grau de maturidade em GC da Tutoria está correto, pois de acordo com os resultados obtidos e conforme a Figura 1 constata-se que a tutoria se encontra no segundo nível de maturidade em GC, onde já se apresenta uma iniciação em GC, ou seja, a tutoria começa a reconhecer a necessidade de gerenciar o conhecimento, porém, pratica este de modo informal, não é institucionalizado e gerenciável.

O Nível de maturidade em GC é uma escala de medida onde se pode avaliar a capacidade e o nível de preparação de uma organização em utilizar de forma adequada seus ativos intelectuais ou capital intelectual (BATISTA, 2011). Com um diagnóstico da GC é possível a organização saber os pontos fortes e fraquezas de seus recursos de conhecimento, e essa informação pode ser utilizada como base para a geração ou atualização do seu planejamento de ações no ambiente de Gestão de Conhecimento (FRESNEDA et al, 2008).

Com os resultados da avaliação do grau de maturidade em GC é possível conhecer onde estão localizados seus pontos fortes e oportunidades de melhoria, pois os resultados da aplicação do instrumento de avaliação demonstram em quais critérios a Tutoria está mais forte e quais precisam melhorar. Analisando os resultados verificou-se que a Tecnologia é um ponto forte da tutoria, pois foi unânime a resposta dos grupos, este critério ficou em primeiro lugar com uma maior pontuação. Percebeu-se que no critério de Resultados de GC a Tutoria está com a menor pontuação e foi unânime nas respostas dos grupos como em última colocação de critérios que são realizados na Tutoria, gerando assim, um ponto a ser melhorado. Não se esperava algo contrário disso, haja vista que a Tutoria alcançou um nível baixo no grau de maturidade em GC, sendo assim, os resultados relativos à GC não poderiam ser positivos nesta avaliação, pelo fato da tutoria ainda não praticar
GC, começa apenas a reconhecer esta necessidade e institucionalizá-la.

\section{CONSIDERAÇÕES FINAIS}

Este estudo teve como objetivo geral realizar um diagnóstico do grau de maturidade em Gestão do Conhecimento na Tutoria dos Cursos de Graduação na modalidade a distância do Departamento de Ciências da Administração da UFSC.

Os resultados da avaliação do grau de maturidade demonstraram que a tutoria se encontra no estágio de iniciação diante dos estágios existentes de maturidade, ou seja, a tutoria começa a reconhecer a necessidade de gerenciar o conhecimento, porém, pratica este de modo informal, não é institucionalizado e gerenciável.

Observou-se que o grau de maturidade da tutoria em GC é baixo. Com exceção do critério "Tecnologia”, em que a tutoria obteve a pontuação de 21,4, em todas as demais a pontuação alcançada ficou abaixo de 16,92 se comparado com a pontuação máxima possível, o que revela o baixo grau de maturidade. Em outras palavras, há muito que fazer em todos os sete critérios para institucionalizar a GC na tutoria. O Gráfico 1 evidencia claramente os resultados da avaliação geral dos grupos em cada critério.

Uma avaliação da maturidade organizacional serve como um guia quanto à forma de evolucionar e gerenciar uma organização por meio da identificação de oportunidades de melhoria contínua, dos processos e procedimentos necessários, das tecnologias e sistemas de informação mais adequados, da comparação com outras organizações, da forma como estão gerindo as pessoas, bem como da identificação de indicadores que evidenciem suas potencialidades (BRUNO, 2008).

O objetivo fundamental de uma avaliação da maturidade de GC é o de extrair mais valor do conhecimento existente e que está sendo pouco utilizado. É o de auxiliar as organizações a avaliar e entender seu nível atual de maturidade organizacional, provendo um caminho para melhoramento através do mapeamento e reconhecimento das competências que deveriam desenvolver. É o de verificar lugares, situações onde há uma "não utilização adequada 
de conhecimento", onde pode ser melhorado e mais explorado.

Deste modo, a Tutoria precisará superar desafios para modificar o atual cenário, pelo baixo grau de maturidade em GC, e avançar na institucionalização da Gestão do Conhecimento. Alguns desses desafios são mais simples, outros mais complexos. Uns poderão ser superados no curto prazo, outros determinarão mais tempo. Todos eles, no entanto, exigirão comprometimento e constância de propósito da alta administração (Chefias e Coordenação) envolvimento das chefias intermediárias (Supervisores de Tutoria) e participação ativa dos tutores e o pessoal da TI.

O diagnóstico do grau de maturidade da Tutoria servirá de subsídio para a elaboração de um plano de gestão do conhecimento para Tutorias. Um plano baseado em um modelo de GC pode contribuir de maneira decisiva para a aplicação de um processo de GC de forma sustentada, além de propiciar à gestão de Tutorias de cursos a distância o Aprendizado Organizacional, que contribuirá para os processos, através da renovação continuada do conhecimento.

Como sugestão da autora, recomenda-se que os gestores articulem práticas de GC que proporcionem a tutoria a produzir conhecimento a fim de contribuir para o planejamento dos cursos; que articulem e disseminem conhecimento para aperfeiçoar a tutoria; que realizem a implementação de um repositório digital de conhecimentos da tutoria; que modelem ou revejam os processos de produção coletiva, de avaliação e disseminação do conhecimento produzido pela equipe da tutoria; que promovam de forma mais intensa a transferência de conhecimento de especialistas renomados de diversas áreas do conhecimento, com treinamentos, capacitações, etc.; que ampliem os meios de disseminação internos de compartilhamento e disseminação de informações e dos conhecimentos produzidos na tutoria e; que mapeiem e disseminem as competências individuais.

\section{REFERÊNCIAS}

ALMEIDA, Maria Elizabeth Bianconcini de; TERÇARIOL, A. A. L.; MENDES, M.; BANCOVSKY, R. O Processo de Gestão de Projetos em EaD: Tecendo Algumas Considerações a Partir do Projeto Gestão Escolar e Tecnologias. In: RIBIE - VIII Congresso Iberoamericano de Informática Educativa, San Jose, 2006.

BARROS; A. J. da S.; LEHFELD, N. A. de S. Fundamentos de metodologia científica. São Paulo: Pearson Prentice Hall, 1986.

BATISTA, F. Modelo de gestão do conhecimento para a administração pública brasileira: como implementar a gestão do conhecimento para produzir resultados em benefício do cidadão/Fábio Ferreira Batista. - Brasília: Ipea, 2012.

BINOTTO, Erlaine. Criação de conhecimento em propriedades rurais no Rio Grande do Sul, Brasil e em Queensland, Austrália. 2005. Tese (Programa de Pós-Graduação em Agronegócios) - Universidade Federal do Rio Grande do Sul, Porto Alegre, 2005.

\section{BRUNO, Gabriella Diniz. Maturidade em Gestão} do Conhecimento: um estudo sobre as empresas do setor elétrico. 2008. Dissertação (Programa de PósGraduação e Pesquisa em Administração e Economia) Faculdade de Economia e Finanças IBMEC, Rio de janeiro, 2008.

BUKOWITZ, Wendi R.; WILLIAMS, Ruth L. Manual de Gestão do Conhecimento: ferramentas e técnicas que criam valor para a empresa. Porto Alegre: Bookman, 2002.

CORREIA NETO, J. F. Elaboração e avaliação de projetos de investimento: considerando o risco. Rio de Janeiro: Elsevier, 2009.

DAVENPORT, Thomas H. Ecologia da informação: porque só a tecnologia não basta para o sucesso na era da informação. São Paulo: Futura, 1998. 
DIAS, Emerson de Paula. Conceitos de gestão e administração: uma revisão crítica. REA, v. 1., n. 1, 2002, p. 1-12. Disponível em: <http://periodicos. unifacef.com.br/index.php/rea/article/view/160/16>. Acesso em 10.jul.2017

FRESNEDA, P. S. V.; GONÇALVES, S. M. G.; PAPA, M.; FONSECA A. F. Diagnóstico da Gestão do Conhecimento nas Organizações Públicas: utilizando o Método OrganizationalKnowledge Assessment (Oka). II Congresso Consad de Gestão Pública - Painel 20: Gestão do conhecimento e inovação para a melhoria da gestão pública, 2008.

KIDWELL JILLINDA J., VANDER LINDE KAREN M., AND JOHNSON SANDRA L. Applying Corporate Knowledge Management Practices in Higher Education, Educause Quartert, n. 4, p 28-33, 2000.

KÖCHE, José Carlos. Fundamentos de Metodologia Científica: teoria da ciência e prática de pesquisa. 19. ed. Petrópolis: Vozes, 2001.

LAKATOS, Eva Maria; MARCONI, Marina de Andrade. Técnica de pesquisa. São Paulo: Atlas, 1996.

MARION, J. C. MARION, A. L. C. Metodologias de ensino na área de negócios. São Paulo: Atlas, 2006.

MEYER JUNIOR., Victor; MURPHY, Patrick. Dinossauros, Gazelas e Tigres. Novas abordagens da Administração Universitária. Um diálogo Brasil e EUA. Florianópolis: Insular, 2000.

\section{MINISTÉRIODA EDUCAÇÃO (MEC) - Referenciais} de qualidade para educação superior a distância Junho, 2007.

MORAES, Marialice et al. Guia Geral do Curso Gestão e Docência em EaD: Programa Aberta-Sul. Florianópolis: UFSC/UFSM, 2007.

MORESI, Eduardo Amadeu Dutra. Inteligência organizacional: um referencial integrado. Ciência da Informação, Brasília, v. 30, nª 2, p. 35-46, maio/ ago. 2001.
NONAKA, Ikujiro; The Knowledge-creating Company in Harvard Business Review, p. 162-171, july-august 2007

NONAKA, I. \& TAKEUCHI, H. Criação de conhecimento na empresa: como as empresas japonesas geram a dinâmica da inovação. Rio de Janeiro: Campus, 1997

NUNES, Thiago Soares et al. Gestão de Tutoria: o papel do Supervisor de Tutoria. Revista Novas Tecnologias na Educação-Renote, v. 8, n. 1, 2010. Educação a Distância. Disponível em: <http://seer. ufrgs.br/renote/issue/archive $>$. Acesso em: $18 \mathrm{Fev}$. 2013.

NUNES, Carolina Schmitt. O Compartilhamento de Conhecimento entre os Agentes de um Curso na Modalidade EAD: Um Estudo de Caso. 2012. Dissertação (Mestrado em Engenharia e Gestão do Conhecimento) - Programa de Pós-Graduação em Engenharia e Gestão do Conhecimento - Universidade Federal de Santa Catarina, Florianópolis, 2013.

PAULSEN, Morten Flate. Online Education Systems: discussion and definition of terms. NKI Distance Educational, 2002. Disponível em: <http://www. nettskolen.com/forskning/Definition $\% 20$ of $\% 20$ Terms.pdf $>$. Acesso em 08 de Abril de 2013.

PROBST, Gilbert; RAUB, Steffen; ROMHARDT, Kai. Gestão do Conhecimento: os elementos construtivos do sucesso. Porto Alegre: Bookman, 2002.

REIS, Ana Maria Viegas. Ensino a Distância: megatendência atual: abolindo preconceitos. São Paulo: Imobiliária. 1996.

RUMBLE, Greville. A gestão dos sistemas de ensino a distância. Paris: UNESCO,1993.

SANTOS, Neri dos. Apostila didática: A Gestão Estratégica do Conhecimento. UFSC/PPGEP. Florianópolis, 2000. 
SARTORI, A., ROESLER, J. Educação superior a distância: gestão da aprendizagem e da produção de materiais didáticos impressos e on-line. Tubarão, SC: Ed. Unisul, 2005.

SENGE, Peter M. A quinta disciplina: arte, teoria e prática da organização de aprendizagem. São Paulo: Best Seller, 1990.

SOARES, Aline Pereira et al. Conflitos interorganizacionais em equipes que atuam com Educação a Distância (EAD). 2012. V 10, No 3, Dezembro Cinted - Novas Tecnologias na Educação - UFRGS. Disponível em: < https://seer.ufrgs.br/renote/article/ viewFile/36462/23542>. Acesso em: 08 de Abril de 2013.

STANKOSKY, M. A.; BALDANZA, C. Knowledge management: anevolutionary architecture toward enterprise engineering. Reston: INCOSE, 2000.

STEWART, Thomas. Capital intelectual - a nova vantagem competitiva das empresas. Rio de Janeiro: Campus, 1998.

SVEIBY, Erick. Karl. A knowledge-based theory of the firm to guide in strategy formulation. Journal of Intellectual Capital. vol. 2, n. 4, 2001.

SVEIBY, E. K. A Nova Riqueza das Organizações: Gerenciando e Avaliando Patrimônios de Conhecimento. Rio de Janeiro: Campus, 1998.

TEIXEIRA FILHO, J. Gerenciando o Conhecimento: Como a empresa pode usar a memória organizacional e a inteligência competitiva no desenvolvimento dos negócios. Rio de Janeiro: Senac, 2000.

TERÇARIOL, A. A. L.; GARA, E. B. M.; OLIVEIRA, P. C.; BELMUDES, R. C. C. P.; GONCALVES, V. Tecendo um Plano de Gestão para o Projeto de Educação a Distância: Uma Experiência na Educação Superior. In: 14 Congresso Internacional ABED, 2008. pesquisa em administração. São Paulo: Atlas, 2007. 